\title{
Serine/Threonine Protein Kinase
}

National Cancer Institute

\section{Source}

National Cancer Institute. Serine/Threonine Protein Kinase. NCI Thesaurus. Code

C17325.

A class of enzymes that transfer phosphate groups to serine or threonine residues in peptides or proteins. These proteins are involved in the progression of signal transduction pathways. 